\title{
Status, Gaps and Way Forward in Addressing the Chronic Kidney Disease Unidentified (CKDu) in Sri Lanka
}

\section{H. Ranasinghe ${ }^{1, \#}$ and M. Ranasinghe ${ }^{2}$}

${ }^{1}$ Department of Forestry and Environmental Science, University of Sri Jayewardenepura, Sri Lanka

${ }^{2}$ York University, Ontario, Canada

"Corresponding Author:

Mob: 0767778756; E-mail: hemanthi.ranasinghe@gmail.com

\begin{abstract}
Starting in the mid-1990s, Chronic Kidney Disease of Unknown aetiology (CKDu) was discovered among the rice paddy farmers in the North central Province (NCP) of Sri Lanka. Over the next two decades, the disease spread rapidly to the other farming areas. According to the World Health Organisation (WHO) Report of 2012, a minimum of $15 \%$ of people in the age group 15-70 years are affected by CKDu in North Central and Uva Provinces. According to Government Medical Officers Association (GMOA, 2013) of Sri Lanka, total population of 400,000 are effected countrywide. Total number of deaths due to CKDu is 1400 annually while the death rate of the North Central Province is 19 per month which is the island's highest (Athuralia et al., 2009). Over the past 12 years numerous studies have been undertaken by a range of institutions in relation to the problem and, as a result, a body of research has been established. However, most of these studies were confined to each discipline and there was no interconnection between the disciplines although the disease and its effect goes beyond disciplines. By 2008, the $C K D$ u problem received national prominence and the Government of Sri Lanka invited the World Health Organisation (WHO) to look into the problem through a systematic study, referred to as the National Research Program that was funded by the National Science Foundation and the WHO. Based on the recommendations of the $\mathrm{WHO}$, the Government established an Inter-ministerial Committee comprising of the Ministries of Agriculture, Water Supply and Drainage, Social Services. In 2015, a Presidential Task Force was also formed to provide leadership and facilitation to this interdisciplinary task. This article attempts to review the current status of the action taken in combating the CKDu based on the said recommendations and provide guidance for the preparation of a road map to achieve the goal of eliminating the disease from the country.
\end{abstract}

KEYWORDS: CKDu, Inter-ministerial committee, Road map, Socio-legal, WHO recommendations 


\section{Introduction}

Starting in the mid-1990s, Chronic Kidney Disease of Unknown aetiology (CKDu) was discovered among the rice paddy farmers in the North Central Province (NCP) of Sri Lanka in Anuradhapura and Polonnaruwa Districts. The disease has now spread to neighbouring districts in the North Western, Eastern, and Uva as well as the Central and Northern Provinces. The $\mathrm{CKDu}$ prevalent area covers approximately $17,000 \mathrm{~km}$ with a predominantly rural population of 2.5 million (Chandrajith et al., 2011). CKD is the most prevalent among male farmers in the 40 to 60 age group engaged in rice cultivation, although lately, it has also been detected among women, children, and even cattle (Centre for Science and Environment, 2012).

There is scientific consensus that this fatal disease in Sri Lanka is not related to known causes commonly identified with kidney disease, such as, diabetes, hypertension, obesity, or other factors such as snake bite (Ministry of Healthcare and Nutrition, Epidemiology Unit, Sri Lanka and World Health Organization, 2009). The exact cause of this disease is being determined. The WHO and the Sri Lankan Government continue to designate it as "Chronic Kidney Disease of Unknown Aetiology" (Ministry of Healthcare and Nutrition, Epidemiology Unit, Sri Lanka and World Health Organization, 2009). This rare form of tubule- interstitial disease involves slow, asymptomatic progressive kidney damage over 3 or more months, making diagnosis and treatment difficult. Nearly $80 \%$ of patients experience total kidney failure within 2 years following diagnosis. Given the inadequacy of medical services, the high cost of treatment such as dialysis and organ transplantation and the poverty of most victims, death becomes inevitable for most (Handunnetti and Daniel, 2012).

A group of Sri Lankan doctors had estimated that as many as 400,000 people in Sri Lanka's North Central region may be affected by the disease (Perera, 2012). Some 22,000 people have died from CKDu over the past 2 decades in the NCP with at least 5 or 6 out of 100 people currently affected (Gunawardena, 2012). The death rate of the North Central Province is 19 per month which is the island's highest (Athuralia et al., 2009).

Over the past 12 years numerous studies have been undertaken by a range of institutions in relation to the problem and, as a result, a body of research has been established. They range from hospital cohort and community level studies; water resource studies; assessments of food sources; and studies into possible genetic linkages. Several of these studies have been published in peer-reviewed journals along with a substantial quantity of material in 'grey literature'. However, most of these studies were confined to each discipline and there was no interconnection between the disciplines although the disease and its effect goes beyond disciplines. By 2008, the CKDu problem received national prominence and the Government of Sri Lanka invited the World Health Organisation (WHO) to look into the problem through a systematic study, referred to as the National Research Program that was 
funded by the National Science Foundation and the WHO. Results of the study indicated that $15 \%$ of the people in the North Central Province are affected by $\mathrm{CKDu}$. According to them, no single agent is responsible for the pathogenesis of the $\mathrm{CKDu}$. Among the causative factors, low levels of cadmium which entered the body through the food chains coupled with deficiency of selenium, concurrent exposure to Arsenic and pesticides were mentioned. They did not identify water as a source of exposure but improving water quality and supply of water with less hardness was expected to reduce the body burden of heavy metals as well as minimize the possible role of fluoride, hardness, calcium and sodium. The findings were published in 2012. Based on these recommendations, the Government of Sri Lanka appointed an Inter-ministerial Committee to review the situation especially the possible causes and provide remedial action. In October 2012, an Inter-ministerial Officials Committee was appointed for the CKDu and also 4 subcommittees appointed by the Ministerial/Officials Committee. The Ministries which were identified as direct stakeholders were Ministry of Health, Ministry of Agriculture, Ministry of Social Services, Ministry of Water Supply and Drainage. In 2015, a Presidential Task Force was formulated with a view to eradicate the disease by harnessing and sharing knowledge, application of best practices, preventing occurrence and guaranteeing treatment and ensuring welfare of the affected through a process of coordination.

This article attempts to review the current status of the action taken in combating $\mathrm{CKDu}$ based on the above and provide recommendations for further action taking an inter disciplinary approach with socio-legal, economic, environmental and corporate social responsibility implications in addressing the disease rather than secular approaches. Table 1 outlines the sectoral recommendations and the responses/actions taken by the respective agencies so far in combating the disease.

Table 1: The sectoral recommendations and the responses/actions taken by the respective agencies in combating the disease

\begin{tabular}{|c|c|c|}
\hline Sector & WHO Recommendations & $\begin{array}{c}\text { Actions Already Taken/ } \\
\text { Being Taken }\end{array}$ \\
\hline \multirow[b]{2}{*}{ Agriculture } & $\begin{array}{l}\text { Establishment of Statutory } \\
\text { Technical Council to promote } \\
\text { environmentally friendly agriculture }\end{array}$ & \\
\hline & $\begin{array}{l}\text { Establishment of new Sri Lankan } \\
\text { Standards (SLS) on pesticides and } \\
\text { agrochemicals }\end{array}$ & $\begin{array}{l}\text { Some work done by the Registrar of } \\
\text { Pesticides but needs to be improved } \\
\text { with the novel information from } \\
\text { research and best practices } \\
\text { worldwide. }\end{array}$ \\
\hline
\end{tabular}


To make orders under the Pesticide Control Act to retain heavy metals and impurities to a minimum possible level

This is already included in the National Pesticide Act
Establishing methodology for controlling under-growth (weeds) of paddy cultivation and encouraging farmers to cultivate alternate crops for minimizing the use of pesticide
There are sporadic efforts to use indigenous technologies/organic methods for this but no concerted effort has been taken.

Council for Agricultural Research Policy (CARP) promotes organic agriculture in the country.

To prohibit the use of Propane,

Glyphosate, Carbaryl and Chlorpyrifos which have been identified as harmful pesticides in areas where kidney diseases are spreading
Glyphosate was banned island wide. The others were banned in areas with CKDu incidence

\section{Agriculture}

Strengthening legal framework to authorize state officials including the health sector \& Grama Niladhari to take legal action against those resorting to indiscriminate use of pesticides and those supporting the same

No such framework in place.

In view of the health risk, taking measures to minimize the use of all chemical fertilizers while encouraging farmers to adopt alternative methods
Not done nationally although conducted by certain projects sporadically.
Minimise the use of imported phosphate and increase production and use of local phosphates
The processing of phosphate in Eppawala is being looked into. 
Testing all fertilizer varieties with health risk posed due to heavy metal and toxic ingredient content and establishment of revised standard for the same
Certain efforts done by the Registrar of Pesticides
Strengthening of legal background $\&$ establishment of laboratory facilities for frequent testing of agro-chemical impurities
Due to high cost these parameters are not tested during regular testing by institutions
Educate the public on the harmful effects on human health due to the use of agro-chemicals and their safety and efficient use
The educational/awareness programs done but needs consistency

Prohibit pesticide and agrochemical fertilizer advertising over electronic and print media

Some regulation exercised by Registrar of Pesticides.

\section{Agriculture}

Establishment of a safety method for recycling/disposal of empty pesticide containers/bottles and To be done fertilizer bags

Impose a $10 \%$ health safety cess on all imported pesticide varieties and the levied amount to be used for welfare of the kidney patients and research activities

Establishment of legal provisions for mandatory requirements in relation to standards
To be done 


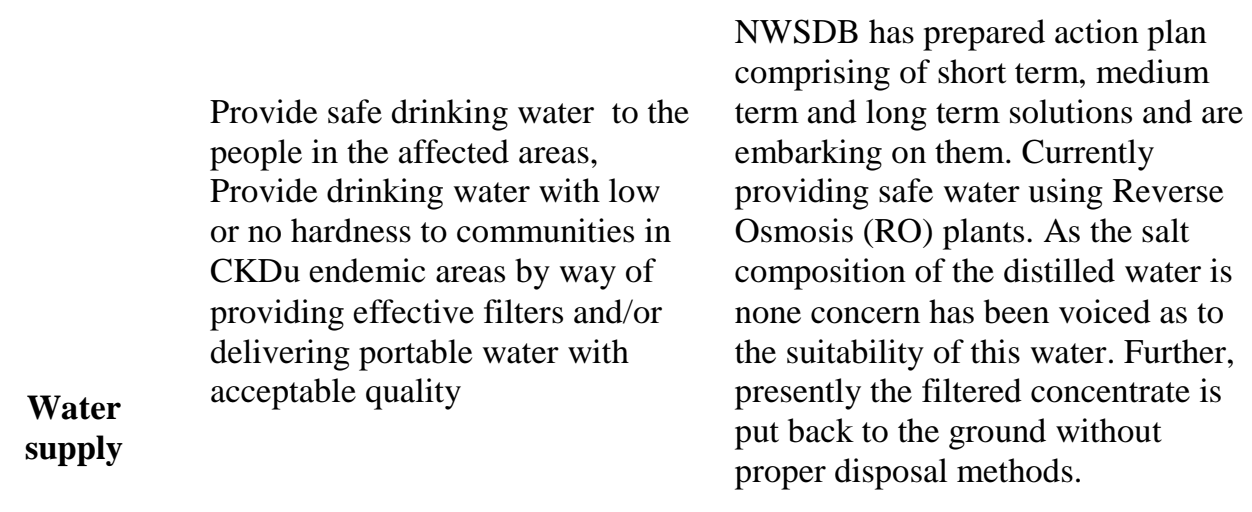

Promote \& implement rain water harvesting structures with quality monitoring systems and make regulations for all new buildings Very limited effort in place. Needs in CKDu areas to be equipped enhancement. with rain water harvesting units.

To pay monthly assistance of Rs. 1500 each for kidney patients who do not require dialysis
Action taken by the Ministry of Social Services.
To pay monthly assistance of Rs.

Social $\quad 3000$ each for kidney patients who require dialysis
Action taken by the Ministry of Social Services.

Establish appropriate CSR

avenues through Banks, Insurance companies, NGOs, local institutions for possible subsidy or To be done. incentives for proposed curative and corrective measures. 
Establish river banks, green manure banks, neem avenues, herbal gardens, compost bays and strict declaration of non-toxic zones
Despite the fact that the Irrigation Ordinance, Mahaweli Authority Act and National Environmental Act include leaving of reservations beside the water courses this is not practiced in the country in general.

Farmer organisations are present but this is not necessarily included in the responsibility.
Identify farmers/farmer groups

\section{Environment} and designate them as responsible agents/agri environment guards with authority to regulate the inputs used in agriculture
Conduct extended cost benefit analysis for the use of agrochemicals in consideration of their impact on environmental \& social effects
Not done yet.
Establish a high powered policy implementation body to carry out further research on establishing the exact causal factors of CKDu and to control CKDu and CKD under an appropriate ministry and to coordinate and implement the recommendations
The Coordinating Secretariat for Science, Technology and Innovation (COSTI) is coordinating this effort to a certain extent.

\section{Research}

and

Development Establish an independent accredited laboratory \& upgrade the existing laboratories with facilities such as trained staff \& sophisticated equipment to analyse trace elements $(\mathrm{Cd}, \mathrm{As}, \mathrm{Pb}, \mathrm{Fe}, \mathrm{Mn}$ etc.) pesticide residues $\&$ other elements related to CKDu.

This effort is being addressed to a certain extent although not to the Grama Niladhari Divisional levels. identify all CKDu hotspots up to Grama Niladhari Division
Sporadic efforts are done especially with research projects. However, the laboratories which collect time series water quality testing (i.e. NWSDB) do not include pesticides and also address heavy metals to a limited extent due to high cost of analysis.

Prepare necessary maps indicating zones for active, potential and prone to agrochemical

No concerted effort on this. contamination 
Implement an integrated awareness program to address all important aspects of CKDu and to promote suitable agricultural Programs are done sporadically but practices needs a concerted effort with proper monitoring for impact

Awareness

Include the impact of heavy metals on human health \& environment and safe use of pesticides and fertilizer into curricular of To be done Geography, Agriculture, Health Science and science in secondary schools

\section{Issues in the Implementation of the Proposed Recommendations}

Despite the fact that an Inter-Ministerial Committee had been appointed to coordinate the activities taken by each Ministry in this regard, the inter disciplinary nature of viewing this problem and fetching solutions has not proved satisfactory and needs strengthening. There were other functional drawbacks in both socio legal, environmental and corporate social responsibility perspectives as detailed below;

\section{Socio-Legal Implications}

Among the Acts which are already in place, the National Agriculture Act, The National Pesticide Act, The National Environmental Act, The Mahaweli Act have a direct stake to the disease incidence and the response. Ensuring healthy ecosystems is a prime concern of the National Environment Act but in most of the agricultural areas this aspect had been overridden by pure economic development which is dominated by the humankind. Despite the fact that the Mahaweli Act spells out the requirement to allocate reservations/buffers surrounding/on either side of the water courses this is rarely been done on the ground and agriculture is being practiced up to the brim of the water courses thus making them vehicles of transport of the residues of agrochemicals. Despite the fact that it was well established that inorganic constituents especially some heavy metals in fertilizer has a stake in causing the illness, there is no concerted effort in discouraging the every increasing use of inorganic fertilizer. Despite the fact that promoting organic agriculture is included in the National Agriculture Act it generally receives step mothers treatment. Fertiliser subsidies are given to the inorganic fertilisers/agrochemicals but none for the organic fertilizers. With regards to the agrochemical industry, there is a growing opposition not only among the corporates who import agrochemicals but others who are related in different ways towards the actions taken to ban certain agrochemicals with toxic constituents which had been banned in other parts of the 
world. International codes of conduct, certifications and green accountabilities are already in place in these multinational companies but perhaps the impact of human health had been overlooked in the process? The Ministry of Environment, despite their mandate given by the National Environment Act to ensure healthy ecosystems had not taken an active role in addressing the CKDu hitherto. With regards to harnessing social capital to provide psychosocial support to the affected communities, there is only sporadic efforts led by mostly the religious leaders in villagers. This is a disappointing situation especially since Sri Lanka is a country nourished with major religions, philosophies and a rich and caring culture.

Some recommendations for Action to enhance the inter disciplinary nature of support by Government, private sector, NGO, communities etc. towards combating $\mathrm{CKDu}$ is shown below;

- Maintain the ban of Glyphosate Island wide. Ban the others with the active ingredients Propanil, Carbaryl, Choloropyrifos and Carbofuran too island wide. Propanil, Carbaryl, Choloropyrifos and Carbofuran have been banned in other countries due to adverse impacts on human health.

- Ministry of Environment to take the lead in ensuring the safe administration of agrochemicals by way of providing permits, certification etc. for the merchants/distributors/applicators etc.

- Ministry of Environment to impose polluter pay principle and along with the $10 \%$ of Cess from imports of agrochemicals build up a fund and provide assistance to affected families, researchers, equipment etc. as necessary

- Promote the organic farming as a national campaign including awareness, incentives, connecting farmers with markets, subsidies for organic fertilisers, disincentives for use of inorganic agrochemicals etc.

- The Ministry of Environment to collaborate with MASL and Ministry of Irrigation to ensure reservations are maintained adjacent to water courses. These reservations could be planted up with indigenous mixed vegetation.

- NWSDB to step up the regular water quality testing procedures to test for heavy metals and agrochemicals in all the water bodies in areas having potential for $\mathrm{CKDu}$

- The disposal of the concentrate of the Reverse Osmosis (RO) to be done in an environmentally friendly manner (i.e. by pond systems) and not to let it out to the environment as being done now.

- The water in the RO plants need to be enriched with essential nutrients. 
- Rainwater harvesting needs to be promoted with good standards and monitoring. This has to be included in the building codes and made mandatory.

- Carry out surveys using GIS to identify all CKDu hotspots up to Grama Niladhari Divisions

- Declare CKDu hotspots and take all initiatives to establish casual factors and to mitigate $\mathrm{CKDu}$ in the prevalent areas

- Great emphasis placed on early detection using early testing of samples by mobile labs, using bio markers and then treating patients with early symptoms

- Patient care should include both indigenous and western medicines coupled with lifestyles changes. Psycho social support need to be provided to them and their families both in the villages and in hospitals. This can be done by mobilising social capital in the village (temple, church, NGOs, fellow patients and families, aid workers, health care personnel) which will facilitate them to lead a normal life until the end.

- Increase the allowance paid to the patients and their families through banks using Cess, polluter pay and CSR funds

- Step up the awareness programme on $\mathrm{CKDu}$ using all personnel in ministries as well as media effectively

\section{References}

Athuralia, N. T. C., T. D. J. Abeysekara, P. H. Amerasinghe, R. Kumarasiri and V. Dissanayake (2009). "Prevalence of chronic kidney disease in two tertiary care hospitals: High proportion of cases with uncertain aetiology". Ceylon Medical Journal, 54: 23-25.

Centre for Science and Environment. (2012). "Environmental contamination and its association with Chronic Kidney Disease of Unknown Aetiology in North Central Region of Sri Lanka".

Chandrajith, R., S. Nanayakkara, K. Itai, T. N. C. Aturaliay, C. B. Dissanayake, T. Abeysekara, A. Koizumi (2011). "Chronic kidney diseases of uncertain aetiology (CKDue) in Sri Lanka: Geographic distribution and environmental implications". Environmental Geochemistry and Health, 33: 267-278.

GMOA. (2013). Government Medical Officer's Association of Sri Lanka Press Release. Available online:

http://www.lakbima.lk/oldpapers/daliylakbima/2013/November/last_13_11_1. 
Gunawardena, N. (2012). "Science and politics of mass kidney failure in Sri Lanka". Available online: http://groundviews. org/2012/08/19/science-and-politics-of-masskidney-failure- in-sri-lanka/.

Handunnetti, D. and S. Daniel (2012). "Conflicting reports highlight scientific data gaps in Sri Lanka's chronic kidney disease". SciDevNet. Available online: http://www.scidev.net/en/south- asia/features/conflicting-reports-highlight-scientificdata- gaps-in-sri-lanka-s-chronic-kidney.html.

Ministry of Healthcare and Nutrition, Epidemiology Unit, Sri Lanka and World Health Organization. (2009). "Chronic Kidney Disease of Unknown Aetiology (CKDu): National research programme for the Chronic Kidney Disease of Unknown Aetiology $(\mathrm{CKDu})$ in Sri Lanka”.

Perera, A. (2012). "Study links kidney disease in Sri Lanka's farm belt to agrochemicals". Inter Press Service. Available online: http://www.ipsnews.net/2012/08/study-linkskidney-disease-in-sri-lankas-farm-belt-to-agrochemicals/ PML/PR-42/2012.

Registrar of Pesticides. "List of Banned Pesticides in Sri Lanka".

World Health Organisation. (2012). "Investigation and evaluation of Chronic Kidney Disease of Uncertain Aetiology". 